\title{
Body Self-Image, Eating Attitudes and Quality of Life among Regular, Moderate and Non-Exercisers
}

\author{
NandiniSanyal* ${ }^{\star}$, Tina Fernandes**, Ritika Matta ${ }^{\beta}$ \\ *Asst. Prof., Dept. of Psychology, St. Francis College for Women, Begumpet, Hyderabad - 500016. \\ **Head, Dept. of Psychology, St. Francis College for Women, Begumpet, Hyderabad - 500016. \\ ${ }^{\beta}$ Graduate Student, St. Francis College for Women, Begumpet, Hyderabad - 500016 \\ ${ }^{t}$ Direct all correspondences to NandiniSanyal
}

\begin{abstract}
The present study aims to observeif there is a relationship between body self-image, eating attitudes and quality of life in men and women engaged in regular, moderate and no exercise. A non-probability purposive sampling technique was employed to select a sample of 193 young unmarried adults aged between 2030 years.The Body Self-Image Questionnaire (BSIQ) (Rowe, 1999), theEating Attitudes Scale (EAT-26) (Garner, 1982) and the Quality Of Life questionnaire (WHOQOL-BREF, 1991)were administered to the participants. The results indicated significant differences betweenregular, moderate and non-exercisers with respect to body self-image and eating attitudes $(\mathrm{p}<0.05)$. The analysis also revealed significantgender differenceswith respect to body self-image and quality of life $(p<0.05)$. Body self-image, eating attitudes and quality of life were found to be significantlycorrelatedin the three groups $(p<0.05)$. The study highlights the need to bring about awareness in schools, colleges and work places about the importance of physical exercise and its effect on building positive self-perception and self-esteem and thereby improve the quality of life and levels of happiness in individuals.
\end{abstract}

Keywords:body self-image, eating attitudes, exercise, gender, quality of life, unmarried young adults

\section{INTRODUCTION}

Body image is the picture that a person has of his or her physical appearance (Stunkard\& Mendelson, 1967). It is the attitude and perception of oneself in relation to his physical characteristics (Cash \&Pruzinsky, 1990). The body self-image perception can be related to self-esteem, confidence, eating attitudes, participation in physical exercise, attention to grooming, experiences, sexual motivation and emotional stability (Cash \&Pruzinsky, 1990).

Women often engage in exercise to achieve the perfect female body or as close to the ideal body shape. This desire to achieve a perfect body serves as a motivation for women to exercise (Krane\&Waldron, 2001). Women engage more in physical exercise to achieve a thin body than for the pursuit of good health (Davis, 1992). Exercise is a subset of physical activity in which a person engages in a planned, structured and repetitive bodily movement in order to enhance or maintain one or more elements of physical fitness (Caspersen, Powell \& Christenson, 1985). Exercise was associated with an enhanced and improved body selfimage (Hausenblas\& Fallon, 2006).

Regular exercise is regular physical activity preferably on a daily basis, as part of sports, physical education or planned exercise (Sallis\& Patrick, 1994). Excessive exercise many a times includes the use of exercise to improve appearance or body tone and the experience of guilt following postponement of exercise (Mond, Hay, Rodgers, Owen \&Beumont, 2004).

Physical fitness has become a social obsession (Davis, 1990). In the study conducted by Yee (1987), men were more satisfied by their body image as compared to women. Women indulged in dieting behaviors and showed greater behaviors of eating disorder. According to Cohane (2001), body image dissatisfaction in men was closely associated with distress.

Eating attitudes are the beliefs, thoughts, behaviors and relationship with food (Alvarenga, 2010). Eating disorders are usually related to emotional issues such as control and self-esteem. Eating attitudes are the attitudes of one towards eating. According to (Davis, 1990) it is possible that excessive diet preoccupation and concern about body shape leads to some women to indulge in a strenuous workout.Disordered eating behaviors and attitudes can be linked with depression, anxiety, and low self-esteem (Abrams, Allen \& Gray, 1993). Regular participation in exercise can be related to over concern with weight and dieting (Davis, Fox, Cowles, Hastings \&Schwass, 1990).

The eating habits of obese and morbidly obese individuals are more influenced by emotional triggers. If individuals are irritated, depressed or discouraged, worried, anxious or tense and emotionally upset 
(psychological state), theemotionstend to trigger a desire to eat more than sensory stimulus, and the person might indulge in abnormal eating attitudes (Roberts, 2011). Positive evaluation of one's body often leads to healthy eating behaviors and lessens the practice of binge eating and engaging in unhealthy dieting behaviors (Grogan, 2007). Reading magazines leads to self-objectification and may give rise to eating disorders in men and women (Morry\&Staska, 2001). There is a direct relationship between self-objectification and disordered eating behavior (Fredrickson \&Noll, 1998).

A moderate or a vigorous participation in physical activity is essential to maintain a healthy lifestyle of an individual. Moderate physical activity is a minimum of 3 days per week (30 minutes per session). Moderate to vigorous activities require minimum effort such as brisk walking or walking at a high speed (Sallis\& Patrick, 1994). Women's preoccupation with weight due to the societal pressure and guilt, often gives rise to a distorted body self-image, helplessness and unsuccessful dieting efforts (Rodin, 1984). Dieting behaviors usually precede binge eating, the dieter becomes vulnerable and may indulge in unhealthy binge eating practices and develop numerous eating disordered patterns (Polivy, 1985).

Exercise is linked with higher levels of life satisfaction, happiness and quality of life (Stubbe, 2007).The Quality Of Life as defined by The World Health Organization (WHOQOL, 1995) is the perception of an individual's rank in life with regard to the culture and ethics system they reside in and in relationship with their targets, concerns and standards. It is a broad concept that combines an individual's physical health, psychological health, independence, social relationships and his relationship with the environment he lives in. Regular exercise leads to an enhanced mood, self-concept and work behavior. Also exercise leads to an improved cognitive functioning prior and post indulging in the fitness program (Folkins\& Sime, 1981). Physical activity plays an important role in treating depression and anxiety (Paluska\&Schwenk, 2000). Regular exercise is associated with an improved mental health and an increased level of happiness and well-being (Stubbe, 2007). According to Piqueras(2011), people who engaged in regular physical activity and indulged in healthy eating patterns of behavior were more likely to live a happier life and have a higher quality of well-being.

Frequency of exercise matters for boosting body perceptions, the duration, intensity, length or type of exercise, does not account for enhancing body image (Alexander, 2009).Frequency of exercise can be defined as the number of sessions of physical activity a person engages per day or week(Sallis\& Patrick, 1994). Regular physical exercise can effectively have a positive effect on clinical depression. Regular Exercise can reduce mood states including tension, fatigue, anger and vigor in normal and clinical populations. Exercise has a positive connection in enhancing self-esteem (Pollock et al., 1998). Young women had lower body esteem if their peers and parents valued thinness and made frequent comments on their body appearance.

According to Collett (1984), Success or failure at weight control becomes a symbol of the ability to control life and always remain in a state of anxiety and unhappiness. Exercisers are more satisfied with their life and happier when compared to non-exercisers (Stubbe, 2007). Non-exercisers are those people who exercise only occasionally or do not exercise at all(Davis, 1990). Engaging in moderate exercise session regularly would lead to a stable mood and positive psychological well-being (Hansen, 2001). Exercise plays an important in treating anxiety and other mood related disorders (Hales \& Travis, 1987). Dissatisfaction, coupled with a lot of regard placed on appearance, leads most women to engage in dieting behaviors to obtain the level of thinness. As dieting is not a successful means of long-term weight control, depression results from this sense of failure and helplessness linked with dieting failure. This depression then leads to abnormal eating behaviors that have a negative affect and control over body appearance (McCarthy, 1990).

Stubbe (2007), had studied the quality of life and happiness levels in exercisers and non- exercisers. To the best of the researcher's knowledge, body self-image, eating attitudes and quality of life have not been studied together in exercisers and there is a paucity of such research particularly in the Indian context. Against this backdrop, the present study proposes the following questions for analysis:

- Do regular, moderate and non-exercisers differ in terms of body self-image, eating attitudes and quality of life?

- Is there a relationship between body self-image, eating and quality of life in regular, moderate and nonexercisers?

\section{OBJECTIVES}

1 To observe if there is a role of frequency of exercise (viz., regular, moderate and non-exercise) and gender (men and women) on the dimensions of body self-image (viz., overall appearance evaluation, fatness evaluation, health/fitness evaluation, negative affect, health fitness influence, social dependence, investment in ideals, attention to grooming, height dissatisfaction), eating attitudes (viz., dieting, bulimia and food preoccupation and oral control) and quality of life (viz., physical health, psychological health, social relationships and environment).

2 To determine if there is a relationship between body self-image, eating attitudes, quality of life and their dimensions in regular, moderate and non-exercisers. 


\section{METHOD}

\section{Research Design}

This present study adopts a between groups design to determine whether there are any gender differences between regular, moderate and non-exerciser young adults with respect to the nine dimensions of body self-image (viz., overall appearance evaluation, fatness evaluation, health/fitness evaluation, negative affect, health fitness influence, social dependence, investment in ideals, attention to grooming, height dissatisfaction), three dimensions of eating attitudes (viz., dieting, bulimia and food preoccupation and oral control) and four domains of quality of life (viz., physical health, psychological health, social relationships and environment).The present study also adopts a correlational design to determine whether there is any relationship between body self-image, eating attitudes and quality of life and their dimensions among young adult regular exercisers, moderate exercisers and non-exercisers (men and women).

\section{SAMPLE}

A non-probability purposive sampling technique was used to select a sample of 193 unmarried young adults between the age group 20-30 years. Out of the total sample 65 (33 men and 32 women) were regular exercisers, 64 (33 men and 31 women) were moderate exercisers and 64 (32 men and 32 women) were nonexercisers.

\section{INSTRUMENTS}

Four questionnaires were used for this research. They were:

\section{- Information Schedule}

Participants were asked to provide details regarding their gender, age, education, height, weight,number of days they engaged in physical exercise, the type of physical exercise they engaged in, theirphysical and psychological health and the like in the Information Schedule.

\section{- Eating Attitudes Test (EAT-26)}

The EAT- 26 questionnaire is a refinement of the original test EAT- 40 (1979). Garner and colleagues (1982) constructed the 26-item refinement of the original test. The EAT-26 has been particularly useful as a screening tool to assess "eating disorder risk" in high school, college and other special risk samples such as athletes. The EAT-26 is scored on a 4 point Likert scale, ranging from 3: always, 2: usually, 1: often, other answers $=0$. The 26 items are classified under the following three separate subscales: 1) 'Dieting', 2) 'Bulimia and Food Preoccupation' and 3) 'Oral control' and are extracted from the sum of its respective items. EAT-26 is highly correlated with EAT-40 ( $\mathrm{r}=0.98)$.

\section{- Body Self Image Questionnaire (BSIQ)}

The Body Self-Image Questionnaire (BSIQ) measures body image in young adults. Rowe (1999) developed the BSIQ questionnaire. This questionnaire consists of 39 items to be scored on 5-point Likert scale ranging from (5) 'completely' to (1) 'not at all'.It is subdivided into 9 subscales (overall appearance evaluation, fatness evaluation, health/fitness evaluation, negative affect, health/fitness influence, social dependence, investment in ideals, attention to grooming, and height dissatisfaction). Internal consistency reliabilities range from .68 to .92 .

\section{- WHO Quality Of Life-BREF (WHOQOL- BREF)}

The WHOQOL-BREF is an abbreviated version of the WHOQOL-100 (1991). The instrument comprises of 26 statements to be scored on a 5 -point Likert scale. It consists of four dimensions, namely, physical health, psychological health, social relationships and environment. The scores on each dimension of the scale are scaled in positive direction i.e., high score represents high Quality of Life. The scale has a test-retest reliability of 0.80.The internal consistency of the four domains of the WHOQOL-Bref ranged from 0.66 to 0.80 .

\section{PROCEDURE}

After selecting the measures, a few arrangements were made for data collection. The questionnaires and the Information Schedule were prepared and organized. The researcher visited different gyms, collegesand companies and sought permission for data collection. Rapport was established with the prospective participants and they were made aware that their participation in the study was purely voluntary. They were assured of maintaining confidentiality throughout the study. The young adults who agreed to participate in the study were requested to sign an 'Informed Consent Form'. Next, the Information Schedule was administered. The individuals who met the sampling criteria were screened. On the next appointment the instructions for the questionnaires (namely, the BSIQ, EAT-26 and the WHOQOL-BREF) were given first and the participants 
were requested to respond to the items. There was no fixed time limit for any of the questionnaires. However, the respondents were asked to complete each questionnaire in about 30 minutes.

\section{RESULTS}

Table 1 Results of Two-Way ANOVA and descriptive statistics with Frequency of exercise and gender as the IVs and the 9 dimensions of body self-image, 3 dimensions of eating attitudes and 4 domains of Quality of life as the DVs.

\begin{tabular}{|c|c|c|c|c|c|c|c|c|}
\hline \multirow{3}{*}{ Variables } & \multicolumn{4}{|c|}{ Frequency of Exercise } & \multicolumn{3}{|c|}{ Gender } & \multirow{3}{*}{$\begin{array}{c}\text { Frequency of exercise } \\
{ }^{*} \text { Gender } \\
\text { F }\end{array}$} \\
\hline & Regular & Moderate & Non exerciser & & Men & Women & & \\
\hline & Mean (SD) & Mean (SD) & Mean (SD) & $\mathrm{F}$ & $\operatorname{Mean}(\mathrm{SD})$ & Mean (SD) & $\mathrm{F}$ & \\
\hline Overall Appearance Evaluation & $14.60(3.77)$ & $14.06(2.84)$ & $14.53(3.43)$ & 0.54 & $14.37(3.47)$ & $14.43(3.27)$ & 0.01 & 0.18 \\
\hline Fatness Evaluation & $15.60(5.98)$ & $17.80(8.03)$ & $16.14(5.40)$ & 2.05 & $15.92(6.46)$ & $17.12(6.73)$ & 1.67 & $3.98^{*}$ \\
\hline Health/Fitness Evauation & $19.26(5.19)$ & $18.0(94.44)$ & $16.86(3.96)$ & $4.54^{*}$ & $18.40(4.49)$ & $17.68(4.79)$ & 1.18 & 1.58 \\
\hline Negative Affect & $9.05(4.51)$ & $10.11(4.79)$ & $11.22(9.04)$ & 1.87 & $10.45(7.82)$ & $9.78(4.72)$ & 0.57 & $3.80^{*}$ \\
\hline Health/Fitness Influence & $11.02(2.93)$ & $11.36(3.23)$ & $9.08(2.79)$ & $11.37^{* *}$ & $10.27(3.20)$ & $10.72(3.08)$ & 1.22 & $5.47^{* *}$ \\
\hline Social Dependence & $8.74(3.63)$ & $8.63(3.14)$ & $8.78(2.84)$ & 0.03 & $8.05(3.00)$ & $9.40(3.28)$ & $8.76^{* *}$ & 1.34 \\
\hline Investment In Ideals & $18.78(4.90)$ & $19.11(3.58)$ & $15.66(3.67)$ & $13.98^{* *}$ & $17.64(4.30)$ & $18.07(4.45)$ & 0.61 & 2.08 \\
\hline Attention To Grooming & $8.82(5.31)$ & $8.69(4.18)$ & $8.20(3.75)$ & $7.06^{* *}$ & $8.00(4.68)$ & $9.15(4.45)$ & 0.02 & 1.67 \\
\hline Height Dissatisfaction & $10.49(2.81)$ & $11.70(2.51)$ & $9.97(2.63)$ & 0.36 & $10.76(2.60)$ & $10.68(2.88)$ & 3.28 & 0.18 \\
\hline Dieting & $11.15(9.23)$ & $12.11(7.62)$ & $6.27(5.91)$ & $10.95^{* *}$ & $9.45(7.08)$ & $10.26(9.03)$ & 0.61 & $3.48 * *$ \\
\hline Bulima and Food Preoccupation & $2.75(3.60)$ & $3.41(2.34)$ & $2.73(2.58)$ & 0.01 & $2.85(2.98)$ & $2.67(3.21)$ & 0.17 & $3.25^{*}$ \\
\hline Oral Control & $3.88(3.43)$ & $4.41(3.44)$ & $5(5.44)$ & 1.16 & $4.18(4.63)$ & $4.67(3.74)$ & 0.64 & $4.31 *$ \\
\hline Physica Health & $28.43(5.46)$ & $29.20(8.34)$ & $27.06(3.71)$ & 1.99 & $29.52(7.75)$ & $26.91(3.49)$ & $8.89 * *$ & 0.02 \\
\hline Psychological Health & $23.12(4.32)$ & $22.58(3.00)$ & $23.41(3.37)$ & 0.93 & $23.84(3.51)$ & $22.21(3.54)$ & $10.43 *$ & 1.60 \\
\hline Social Relationships & $11.54(2.43)$ & $11.75(2.45)$ & $11.50(2.33)$ & 0.23 & $11.97(2.19)$ & $11.21(2.54)$ & 5.00 & $3.66^{*}$ \\
\hline Environment & $32.25(4.31)$ & $32.69(4.09)$ & $31.89(5.42)$ & 0.50 & $33.11(4.67)$ & $31.41(4.44)$ & $6.901 * *$ & $4.36^{*}$ \\
\hline
\end{tabular}

df (frequency of exercise $)=2$

df $($ gender $)=1$

Table 2 showing Post-Hoc (Tukey) results of the three frequency exercise groups, with the dimensions of Body self-image and dimensions of Eating Attitudes as the DV'S.

\begin{tabular}{|c|c|c|c|}
\hline Variables & (I) frequency of exercise & $(\mathrm{J})$ frequency of exercise & Mean Difference (I-J) \\
\hline \multirow{3}{*}{ Health/Fitness Evaluation } & \multirow{2}{*}{ regular } & moderate & 1.26 \\
\hline & & non-exerciser & $2.40 *$ \\
\hline & moderate & non-exerciser & 1.14 \\
\hline \multirow{3}{*}{ Health/Fitness Influence } & \multirow{2}{*}{ regular } & moderate & -0.34 \\
\hline & & non-exerciser & $1.94 *$ \\
\hline & moderate & non-exerciser & $2.28 *$ \\
\hline \multirow{3}{*}{ Investment in Ideals } & \multirow{2}{*}{ regular } & moderate & -0.32 \\
\hline & & non-exerciser & $3.13^{*}$ \\
\hline & moderate & non-exerciser & $3.45^{*}$ \\
\hline \multirow{3}{*}{ Attention to Grooming } & \multirow{2}{*}{ regular } & moderate & $-1.21 *$ \\
\hline & & non-exerciser & 0.52 \\
\hline & moderate & non-exerciser & $1.73 *$ \\
\hline \multirow{3}{*}{ Dieting } & \multirow{2}{*}{ regular } & moderate & -0.96 \\
\hline & & non-exerciser & $4.89 *$ \\
\hline & moderate & non-exerciser & $5.84 *$ \\
\hline
\end{tabular}

*p<0.05 Table 1 shows that there is a significant difference between participants with different frequencies of exercise (viz., regular, moderate and non- exercise) in terms of the heath/fitness evaluation dimension of body self image $(\mathrm{F}=4.54, \mathrm{p}<0.05)$. Table 2 shows that the regular exercisers and non- exercisers significantly differed with respect to the above dimension $(\mathrm{p}<0.05)$. As it is evident from mean scores in Table 1 , the regular exercisers $(M=19.26)$ scored higher than non- exercisers $(M=16.86)$ with respect to the dimension of 
health/fitness evaluation. In other words, the fitness level of regular exercisers was more than the fitness levels of non-exercisers.

Table 1 also shows that there is a significant difference between participants with different frequencies of exercise in terms of the heath/fitness influence dimension of body self-image $(\mathrm{F}=11.37, \mathrm{p}<0.01)$. Table 2 shows that the regular exercisers and non- exercisers and the moderate exercisers and non-exercisers significantly differed with respect to the above dimension $(\mathrm{p}<0.05)$, as it is evident from mean scores in Table 1 , the regular exercisers $(M=11.02)$ scored higher than non- exercisers $(M=9.08)$ and the moderate exercisers $(\mathrm{M}=11.36)$ scored higher than non- exercisers $(\mathrm{M}=9.08)$ with respect to the dimension of health/fitness evaluation. In other words, the exercise levels and state of health of regular exercisers was more when compared to non-exercisers and the exercise levels and state of health of moderate exercisers was more than the nonexercisers.

Moreover, Table 1 suggests that there is a significant difference between participants with different frequencies of exercise in terms of the investment in ideals dimension of body self-image $(F=13.98, p<0.01)$. Table 2 shows that the regular exercisers and non- exercisers and the moderate exercisers and non-exercisers significantly differed with respect to the above dimension $(\mathrm{p}<0.05)$, as it is evident from mean scores in Table 1 , the regular exercisers $(M=18.78)$ scored higher than non- exercisers $(M=15.66)$ and the moderate exercisers $(M=19.11)$ scored higher than non- exercisers $(M=9.08)$ with respect to the dimension of investment in ideals. In other words, a well-proportioned body and muscle tone mattered more to regular exercisers when compared with non-exercisers and a well-proportioned body and muscle tone mattered more to moderate exercisers when compared to non-exercisers.

Table 1 further shows that there is a significant difference between participants with different frequencies of exercise in terms of the attention to grooming dimension of body self-image $(F=7.06, p<0.01)$. Table 2 shows that the regular exercisers and moderate exercisers and the moderate exercisers and nonexercisers significantly differed with respect to the above dimension $(\mathrm{p}<0.05)$, as it is evident from mean scores in Table 1, the regular exercisers $(M=8.82)$ scored higher than moderate exercisers $(M=8.69)$ and the moderate exercisers $(M=8.69)$ scored higher than non- exercisers $(M=8.20)$ with respect to the dimension of attention to grooming. In other words, attention to grooming, appearance and maintaining one's self was found to be more prevalent in the regular exercisers when compared to moderate exercise group and maintaining one's self was found to be more prevalent in the moderate exercisers when compared to non-exercisers.

Table 1 also indicates that there is a significant difference between participants with different frequencies of exercise in terms of the dieting dimension of eating attitudes $(\mathrm{F}=10.95, \mathrm{p}<0.01)$. Table 2 shows that the regular exercisers and non- exercisers and the moderate exercisers and non-exercisers significantly differed with respect to the above dimension $(\mathrm{p}<0.05)$, as it is evident from mean scores in Table 1 , the regular exercisers $(M=11.15)$ scored higher than non- exercisers $(M=6.27)$ and the moderate exercisers $(M=12.11)$ scored higher than non- exercisers $(M=6.27)$ with respect to the dimension of dieting. In other words, regular exercisers engaged more in dieting behaviors when compared to non- exercisers and dieting practices were seen to be more prevalent in moderate exercisers than in non- exercisers.

Additionally Table 1 reveals that there was a significant difference between men and women with respect to the social dependence dimension of body self-image $(\mathrm{F}=8.76, \mathrm{p}<0.01)$ and the physical health $(\mathrm{F}=8.89, \mathrm{p}<0.01)$, psychological health $(\mathrm{F}=10.43, \mathrm{p}<0.01)$ and environment $(\mathrm{F}=6.901, \mathrm{p}<0.01)$ dimensions of quality of life. As it is evident from mean scores, the women $(\mathrm{M}=9.40)$ scored higher than men $(\mathrm{M}=8.05)$ on the dimensions of social dependence. On the other hand, the men $(M=29.52, M=23.84$ and $M=33.11)$ scored higher than the women $(M=26.91, M=22.21$ and $M=31.41)$ on the dimensions of physical health, psychological health and environment respectively. In other words, women compared their bodies more in social situations than men. Whereas men showed more work capacity, mobility, self-esteem and financial resources than women.

Lastly, significant interaction effects were observed between frequency of exercise (viz., regular, moderate and non- exerciser) and gender with respect to the fatness evaluation $(\mathrm{F}=3.98, \mathrm{p}<0.05)$, negative affect $(\mathrm{F}=3.80, \mathrm{p}<0.05)$ and health/fitness influence $(\mathrm{F}=5.47, \mathrm{p}<0.01)$ dimensions of body self-image. Similarly significant interaction effects were observed between frequency of exercise and gender with respect to the dieting $(\mathrm{F}=3.25, \mathrm{p}<0.05)$ and oral control $(\mathrm{F}=4.31, \mathrm{p}<0.05)$ dimensions of eating attitudes. In addition, significant interaction effects were observed between frequency of exercise and gender with respect to social relationships $(\mathrm{F}=3.66, \mathrm{p}<0.05)$ and environment $(\mathrm{F}=4.36, \mathrm{p}<0.05)$ dimensions of quality of life. 
Table 3 Results of the correlation between dimensions of Body self-image, Eating Attitudes and quality of life of regular exercisers $(n=65)$.

\begin{tabular}{|c|c|c|c|c|c|c|c|c|c|c|c|c|c|c|c|}
\hline & $\begin{array}{l}\text { Overall Apperarance } \\
\text { Evvaluation }\end{array}$ & $\begin{array}{l}\text { e Fatmess } \\
\text { Evaluation }\end{array}$ & $\begin{array}{l}\text { HealthFitiness } \\
\text { Evaluation }\end{array}$ & $\begin{array}{l}\text { Negative } \\
\text { Affect }\end{array}$ & $\begin{array}{l}\text { HeallhFFitnes } \\
\text { Inffluence }\end{array}$ & $\begin{array}{l}\text { is Social } \mathrm{h} \\
\text { Dependence }\end{array}$ & $\begin{array}{c}\text { Investment In } \\
\text { Ideals }\end{array}$ & $\begin{array}{c}\text { Attention to } \\
\text { Grooming }\end{array}$ & $\begin{array}{c}\text { Height } \\
\text { Dissatisfation }\end{array}$ & Dieting & $\begin{array}{l}\text { Bulimia and Foo } \\
\text { Preaccupation }\end{array}$ & $\begin{array}{l}\text { d Oral P } \\
\text { Control }\end{array}$ & $\begin{array}{l}\text { Physical I } \\
\text { Headth }\end{array}$ & $\begin{array}{l}\text { Sychologic } \\
\text { Health }\end{array}$ & $\begin{array}{l}\text { all Social } \\
\text { Relationships }\end{array}$ \\
\hline Fatness & $-.283 *$ & & & & & & & & & & & & & & \\
\hline Evaluation & & & & & & & & & & & & & & & \\
\hline Fitness & $.466^{* * *}$ & $-320 * *$ & & & & & & & & & & & & & \\
\hline Evaluation & & & & & & & & & & & & & & & \\
\hline $\begin{array}{l}\text { Negative } \\
\text { Affect }\end{array}$ & $-311^{* * *}$ & $.733^{5 \%}$ & $.250 *$ & & & & & & & & & & & & \\
\hline $\begin{array}{l}\text { Fitiness } \\
\text { Influence }\end{array}$ & $.259 *$ & 0.176 & $.297 *$ & 0.072 & & & & & & & & & & & \\
\hline $\begin{array}{c}\text { Social } \\
\text { Dependence }\end{array}$ & 0.171 & $.332^{2 *}$ & 0.044 & $.497^{* * *}$ & $493^{3 *}$ & & & & & & & & & & \\
\hline $\begin{array}{l}\text { Investment In } \\
\text { Ideals }\end{array}$ & 0.207 & 0.169 & 0.223 & 0.158 & $.69^{7 * *}$ & $.441^{* *}$ & & & & & & & & & \\
\hline $\begin{array}{l}\text { Attention to } \\
\text { Grooming }\end{array}$ & 0.104 & 0.442 & 0.046 & $.289 \%$ & $.451^{* *}$ & $.463^{* *}$ & $.6411^{* *}$ & & & & & & & & \\
\hline Height & $.457^{* *}$ & $.274^{*}$ & 0.01 & $.257^{*}$ & 0.198 & $.503^{* *}$ & 0.198 & 0.094 & & & & & & & \\
\hline Dissatisfaction & & & & & & & & & & & & & & & \\
\hline Dieting & -0.014 & $4.78^{* * *}$ & 0.09 & $.386^{* * *}$ & $313^{*}$ & $.524 * *$ & $.411^{* *}$ & . 49 . $^{1 *}$ & $.200^{*}$ & & & & & & \\
\hline $\begin{array}{l}\text { Bulimia and Food } \\
\text { Preoccupation }\end{array}$ & 0.021 & $.260 \%$ & 0.183 & $.30 \%^{*}$ & $.255^{*}$ & $.460^{* * *}$ & 0.089 & 0.103 & 0.139 & $.358^{* * * *}$ & & & & & \\
\hline Oral Control & -0.064 & $.289 *$ & 0.109 & 0.166 & $399^{* * *}$ & $.350^{\text {*** }}$ & $.400 *$ & $.357^{* *}$ & -0.037 & $.512^{* *}$ & 0.195 & & & & \\
\hline Physical Health & $.457 *$ & $-300^{*}$ & 0.151 & $-318^{* * *}$ & -0.195 & -0.238 & -0.111 & -0.156 & $.288^{*}$ & $-.323^{* *}$ & $-330^{03}$ & -0.098 & & & \\
\hline $\begin{array}{c}\text { Psychological } \\
\text { Health }\end{array}$ & 0.147 & $-3922^{* *}$ & $.311^{* *}$ & $-399 * *$ & -0.045 & $-342^{*} *$ & -0.081 & -0.151 & -0.227 & $-368 * *$ & $.253{ }^{*}$ & -0.068 & $.383 *$ & & \\
\hline $\begin{array}{c}\text { Social } \\
\text { Relationships }\end{array}$ & 0.044 & $-311^{* * *}$ & 0.147 & -0.232 & -0.078 & -0.177 & 0.081 & 0.02 & -0.098 & -0.21 & $-366^{24}$ & 0.032 & $.567^{* *}$ & $.430^{* * *}$ & \\
\hline Environment & -0.08 & -0.211 & $.2566^{*}$ & -0.163 & 0.027 & $.296 *$ & 0.08 & 0.082 & $.270 *$ & -0.091 & $\begin{array}{l}-0.189 \\
\end{array}$ & 0.126 & 0.221 & $.5377^{*}$ & $.519^{* * *}$ \\
\hline
\end{tabular}

Table 3 revealed that there is significant negative correlation between the dimension of fatness evaluation and the dimensions of physical health $(r=-0.30, p<0.01)$, psychological health $(r=-0.39, p<0.01)$ and social relationships $(\mathrm{r}=-0.31, \mathrm{p}<0.01)$. In other words, more the perception of one's self to be fat, lesser was their mobility, work capacity, self-esteem and social relationships in regular exercisers.

Table 3 also reveals that there is significant negative correlation between the dimension of negative affect and the dimensions of physical health $(\mathrm{r}=-0.31, \mathrm{p}<0.01)$ and psychological health $(\mathrm{r}=-0.39, \mathrm{p}<0.01)$ In other words, more the regular exercisers felt depressed about their body lesser was their mobility, work capacity and self-esteem. Moreover, Table 3 shows that there is a significant negative correlation between the dimension of social dependence and the dimensions of psychological health $(\mathrm{r}=-0.34, \mathrm{p}<0.01)$ and environment $(\mathrm{r}=-0.29$, $\mathrm{p}<0.05)$ In other words, more the regular exercisers were conscious of their body in social situations lesser was their self- esteem and social relationships.

Table 3 indicated a significant negative correlation between the dimension of bulimia and food preoccupation and the dimensions of physical health $(r=-0.33, p<0.01)$, psychological health $(r=-0.25, p<0.05)$ and social relationships $(\mathrm{r}=-0.36, \mathrm{p}<0.01)$. In other words, more the regular exercisers felt that food controlled their life lesser was their mobility, work capacity, self-esteem and social relationships. Table 3 also shows a significant negative correlation between the dimension of dieting and the dimensions of physical health $(\mathrm{r}=-0.32$, $\mathrm{p}<0.01)$ and psychological health $(\mathrm{r}=-0.36, \mathrm{p}<0.01)$ in regular exercisers.

Table 3 also shows significant positive correlations between overall appearance evaluation dimension and physical health dimension $(\mathrm{r}=0.45, \mathrm{p}<0.01)$. In other words, more the regular exercisers perceived their overall body to look good more was their mobility and work capacity. Table 3 also revealed significant positive correlations between fatness evaluation dimension and dimensions of dieting $(\mathrm{r}=0.47, \mathrm{p}<0.01)$, bulimia and food preoccupation $(\mathrm{r}=0.26, \mathrm{p}<0.05)$ and oral control $(\mathrm{r}=0.28, \mathrm{p}<0.05)$. In other words, more the perception of regular exercisers to be fat more was their engagement in dieting behaviors, bulimic behaviors or avoidance of eating all together. Table 3 also indicated significant positive correlations between health/fitness evaluation dimension and

DOI: 10.9790/0837-2108064457 $\quad$ www.iosrjournals.org $\quad 49 \mid$ Page


dimensions of psychological health $(r=0.31, p<0.05)$ and environment $(r=0.25 p<0.05)$. In other words, more the fitness level of regular exercisers more was their self-esteem and social relationships. Table 3 showed a significant positive correlations between negative affect dimension and dimensions of dieting $(r=0.38, p<0.01)$ and bulimia and food preoccupation $(\mathrm{r}=0.30, \mathrm{p}<0.05)$ In other words, more the regular exercisers felt depressed about their body more was their engagement in dieting behaviors, and/or bulimic behaviors.

In addition, Table 3 indicated a significant positive correlations between health/fitness influence dimension and dimensions of dieting $(r=0.31, \mathrm{p}<0.05)$, bulimia and food preoccupation $(r=0.25 \mathrm{p}<0.05)$ and oral control $(\mathrm{r}=0.39, \mathrm{p}<0.01)$. In other words, more the exercise levels of regular exercisers more was their engagement in dieting behaviors, bulimic behaviors and/or avoidance of eating all together.

Similarly, Table 3 indicates a significant positive correlations between social dependence dimension and dimensions of dieting $(r=0.52, p<0.01)$, bulimia and food preoccupation $(r=0.46, p<0.01)$ and oral control $(\mathrm{r}=0.35, \mathrm{p}<0.01)$. In other words, more the regular exercisers were conscious of their body in social situations more was their engagement in dieting behaviors, bulimic behaviors and/or avoidance of eating all together. Table 3 revealed a significant positive correlations between dimension of investment in ideals and dimensions of dieting $(r=0.41, p<0.01)$ and oral control $(r=0.40, p<0.01)$. In other words, more the regular exercisers perceived body size and body tone to be important more was their engagement in dieting behaviors. Table 3 pointed to a significant positive correlations between attention to grooming dimension and oral control $(r=0.49, \mathrm{p}<0$. In other words, more the regular exercisers groomed and maintained themselves more was their avoidance of eating behaviors. Lastly, Table 3 also showed significant positive correlations between dimension of height dissatisfaction and dimension of physical health $(r=0.24, \mathrm{p}<0.05)$ in regular exercisers. In other words, more the regular exercisers were dissatisfied with their height more was their work capacity and mobility.

Table 4 Results of the correlation between dimensions of Body self-image, Eating Attitudes and quality of life of moderate exercisers $(n=64)$.

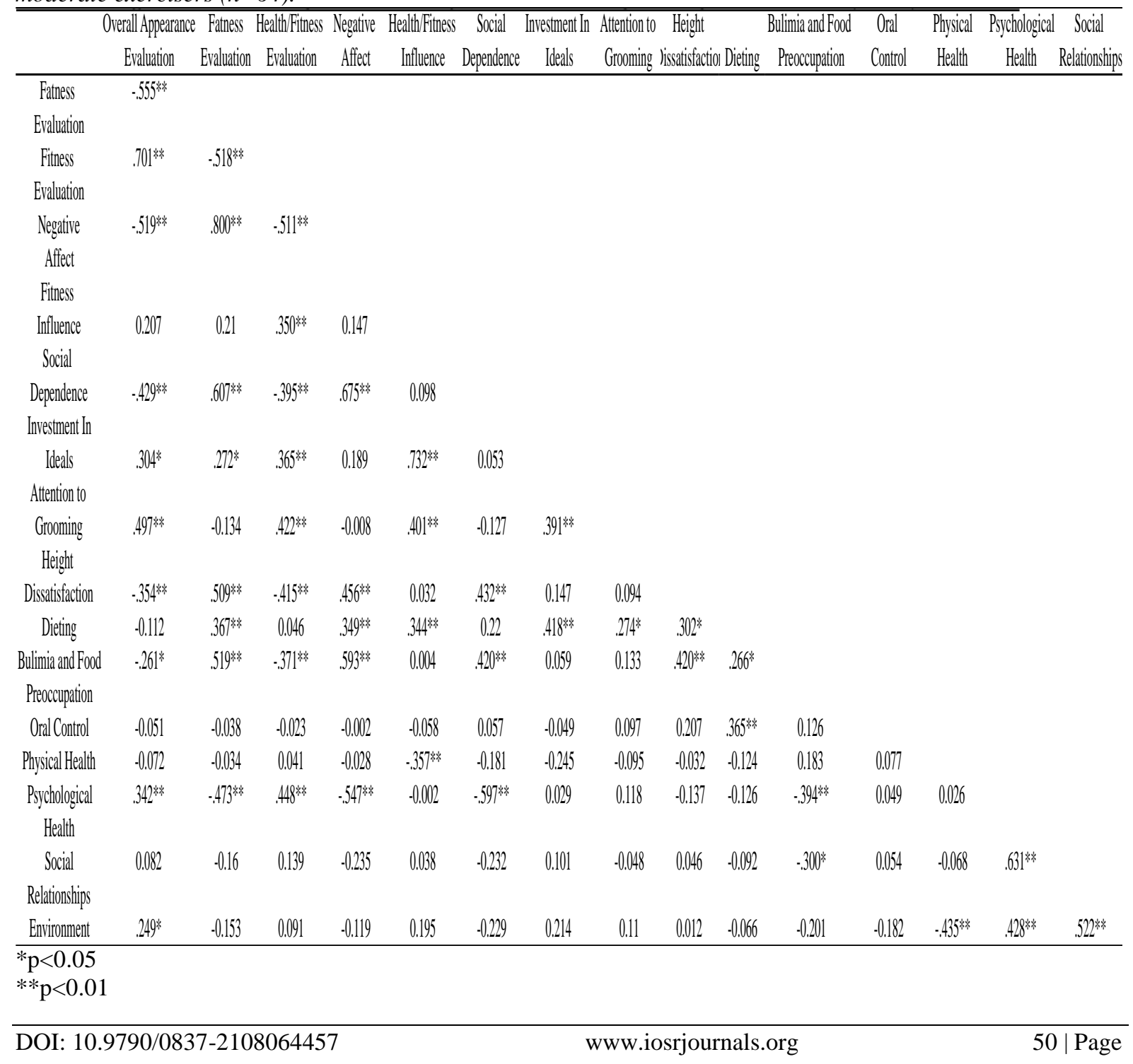


Table 4 revealed that there are significant negative correlations between the dimension of bulimia and food preoccupation and dimensions of overall appearance evaluation $(r=-0.26, p<0.05)$, social relationships $(r=-$ $0.30, \mathrm{p}<0.05)$ and psychological health $(\mathrm{r}=-0.39, \mathrm{p}<0.01)$. In other words, more the bulimic eating behaviors in moderate exercisers lesser will be their belief about their overall body looking good, social relationships and self-esteem. Table 4 revealed that there is significant negative correlation between fatness evaluation dimension and psychological health dimension $(\mathrm{r}=-0.47, \mathrm{p}<0.01)$. In other words more the perception of one's self to be fat lesser was the self-esteem in moderate exercisers. Table 4 revealed that there is significant negative correlations between the health/fitness evaluation dimension and bulimia and food preoccupation $(r=-0.37, p<0.01)$. In other words more the fitness level of moderate exercisers lesser was their engagement in bulimic patterns of eating behaviors.

Table 4 revealed that there is significant negative correlation between negative affect dimension and psychological health dimension $(r=-0.54, \mathrm{p}<0.01)$. In other words, more the moderate exercisers felt depressed about their body lesser was their self-esteem. Table 4 revealed that there is significant negative correlation between health/fitness influence dimension and physical health dimension $(r=-0.35, p<0.01)$. In other words more the exercise levels of moderate exercisers lesser wastheir mobility and work capacity.

Additionally Table 4 also shows significant positive correlations between overall appearance evaluation dimension and dimensions of psychological health $(r=0.34, p<0.01)$ and environment $(r=0.24$, $\mathrm{p}<0.05)$. In other words, more the moderate exercisers perceived their overall body to look good more was their self-esteem and financial resources. Table 4 revealed that there is significant positive correlation between fatness evaluation dimension and dimensions of bulimia and food preoccupation $(\mathrm{r}=0.51, \mathrm{p}<0.01)$ and dieting $(\mathrm{r}=0.36, \mathrm{p}<0.01)$. In other words, more the perception of moderate exercisers to be fat more was their engagement in dieting behaviors and/or bulimic eating behavior patterns. Table 4 indicated a significant positive correlation between health/fitness evaluation dimension and dimension of psychological health $(r=0.44, p<0.01)$. In other words, more the fitness level of moderate exercisers more was their self-esteem. Table 4 reveals a significant positive correlation between negative affect dimension and dimensions of dieting $(r=0.34, p<0.01)$ and bulimia and food preoccupation $(\mathrm{r}=0.59, \mathrm{p}<0.01)$. In other words, more the moderate exercisers felt depressed about their body more was their engagement in dieting behaviors and/or bulimic eating behavior patterns. Table 4 also shows significant positive correlation between social dependence dimension and dimension of bulimia and food preoccupation $(r=0.42, p<0.01)$ in moderate exercisers. In other words, more the moderate exercisers were conscious of their body in social situations more was their engagement in bulimic eating behavior patterns.

Table 5 Results of the correlation between dimensions of Body self-image, Eating Attitudes and quality of life of non- exercisers $(n=64)$.

\begin{tabular}{|c|c|c|c|c|c|c|c|c|c|c|c|c|c|c|c|}
\hline & $\begin{array}{l}\text { Overall Appearance } \\
\text { Evaluation }\end{array}$ & $\begin{array}{c}\text { Fatness } \\
\text { Evaluation }\end{array}$ & $\begin{array}{c}\text { Health/Fitness } \\
\text { Evaluation }\end{array}$ & $\begin{array}{c}\text { Negative } \\
\text { Affect }\end{array}$ & $\begin{array}{l}\text { Health/Fitness } \\
\text { Influence }\end{array}$ & $\begin{array}{l}\text { Social I } \\
\text { Dependence }\end{array}$ & $\begin{array}{l}\text { Investment II } \\
\text { Ideals }\end{array}$ & $\begin{array}{r}\text { Attention to } \\
\text { Grooming }\end{array}$ & $\begin{array}{c}\text { Height } \\
\text { Dissatisfaction }\end{array}$ & Dieting & $\begin{array}{l}\text { Bulimia and Food } \\
\text { Preoccupation }\end{array}$ & $\begin{array}{c}\text { Oral } \\
\text { Control }\end{array}$ & $\begin{array}{l}\text { Physical } \\
\text { Health }\end{array}$ & $\begin{array}{l}\text { Psychologica } \\
\text { Health }\end{array}$ & $\begin{array}{l}1 \text { Social } \\
\text { Relationships }\end{array}$ \\
\hline Overall Appearance & 1 & & & & & & & & & & & & & & \\
\hline $\begin{array}{l}\text { Evaluation } \\
\text { Fatness }\end{array}$ & -0.139 & & & & & & & & & & & & & & \\
\hline $\begin{array}{l}\text { Evaluation } \\
\text { Fitness } \\
\text { Evaluation }\end{array}$ & $.506^{* *}$ & -0.087 & & & & & & & & & & & & & \\
\hline $\begin{array}{l}\text { Negative } \\
\text { Affect }\end{array}$ & $-403^{* * *}$ & 0.017 & -0.066 & & & & & & & & & & & & \\
\hline $\begin{array}{l}\text { Fitness } \\
\text { Influence }\end{array}$ & $.270^{*}$ & 0.188 & 0.122 & -0.079 & & & & & & & & & & & \\
\hline $\begin{array}{c}\text { Social } \\
\text { Dependence }\end{array}$ & -0.06 & $.265^{*}$ & 0.192 & 0.239 & 0.165 & & & & & & & & & & \\
\hline $\begin{array}{l}\text { Investment In } \\
\text { Ideals }\end{array}$ & 0.233 & 0.11 & 0.168 & 0.054 & $.530^{* *}$ & $.418^{* *}$ & & & & & & & & & \\
\hline $\begin{array}{l}\text { Attention to } \\
\text { Grooming }\end{array}$ & $.370^{* *}$ & -0.022 & $.443^{* *}$ & 0.01 & $.367^{* *}$ & $.379^{* *}$ & $.528 * *$ & & & & & & & & \\
\hline Height & 0.136 & -0.059 & -0.119 & -0.087 & -0.056 & 0.019 & 0.047 & -0.015 & & & & & & & \\
\hline Dissatisfaction & & & & & & & & & & & & & & & \\
\hline Dieting & 0.167 & $.268 \%$ & 0.19 & 0.13 & 0.22 & 0.189 & $.309 *$ & 0.228 & $.273^{*}$ & & & & & & \\
\hline $\begin{array}{l}\text { Bulimia and Food } \\
\text { Preoccupation }\end{array}$ & -0.064 & 0.17 & -0.069 & 0.242 & 0.155 & 0.199 & 0.025 & 0.027 & 0.037 & $.372 * *$ & & & & & \\
\hline Oral Control & -0.022 & 0.049 & 0.156 & $.272 *$ & 0.028 & 0.041 & 0.021 & 0.098 & $.382 * *$ & $.427 * *$ & $.370^{* *}$ & & & & \\
\hline Physical Health & $.252 *$ & -0.145 & $.311^{*}$ & -0.121 & -0.005 & -0.085 & -0.054 & 0.077 & $-292 *$ & -0.003 & 0.023 & -0.166 & & & \\
\hline $\begin{array}{l}\text { Psychological } \\
\text { Health }\end{array}$ & 0.143 & 0.121 & $.338 * *$ & -0.045 & -0.191 & -0.007 & -0.212 & 0.155 & -0.149 & 0.089 & 0.055 & 0.079 & $.588^{* *}$ & & \\
\hline $\begin{array}{c}\text { Social } \\
\text { Relationships }\end{array}$ & 0.004 & 0.067 & $.330^{* *}$ & 0.09 & 0.018 & 0.026 & 0.043 & 0.122 & -0.048 & 0.088 & 0.03 & 0.159 & $.511^{* *}$ & $.669^{* *}$ & \\
\hline Environment & 0.225 & 0.072 & $.413^{* *}$ & 0.101 & 0.031 & 0.067 & 0.126 & $.281 \%$ & -0.013 & $.250^{*}$ & 0.043 & 0.229 & $.599 * *$ & $.547 *$ & $.661^{* *}$ \\
\hline
\end{tabular}


Table 5 revealed that there is a significant negative correlation between Height dissatisfaction dimension and dimension of physical health $(r=-0.29, \mathrm{p}<0.05)$. In other words, more the dissatisfaction with height of the non- exercisers, the lesser was their ability to work and engage in daily life activities.

Table 5 also revealed that there is a significant positive correlation between overall appearance evaluation dimension and physical health dimension $(\mathrm{r}=0.25, \mathrm{p}<0.05)$. In other words, more the non-exercisers perceived their overall body to look good more was their mobility and work capacity. Table 5 also revealed a significant positive correlation between fatness evaluation dimension and dieting dimension $(r=0.26, p<0.05)$. In other words, more the perception of non-exercisers to be fat more was their engagement in dieting behaviors. Table 5 also showed a significant positive correlation between health/fitness evaluation dimension and dimensions of physical health $(r=0.31, p<0.05)$, psychological health $(r=0.33, p<0.01)$, environment $(r=0.33$, $\mathrm{p}<0.01)$ and social relationships $(\mathrm{r}=0.41, \mathrm{p}<0.01)$. In other words more the fitness level of non-exercisers more was their mobility, work capacity self-esteem and social relationships. Further a significant positive correlation between negative affect dimension and oral control dimension of eating attitudes $(r=0.27, p<0.05)$ was seen. In other words, more the non-exercisers felt depressed about their body more was their avoidance and controlled eating behaviors patterns.

Table 5 further revealed that there is a significant positive correlation between attention to grooming dimension and environment dimension $(\mathrm{r}=0.28, \mathrm{p}<0.05)$. In other words, more the non-exercisers groomed and maintained themselves more was their financial resources and a stable, secure home environment. Table 5 further revealed that there is a significant positive correlation between dieting dimension and environment dimension $(r=0.25, \mathrm{p}<0.05)$ in non-exercisers. In other words, more the non-exercisers engaged in dieting behaviors more was their financial resources and a stable, secure home environment.

\section{DISCUSSION}

The current study found a significant difference in participants with different frequencies of exercise with respect to the dimension of Health/Fitness Influence, it was indicated that regular exercisers and nonexercisers significantly differed with respect to fitness levels. A study conducted by Hoffman (2008), supported this finding, wherein the latter study found significant differences between the three-exercise groups and that in regular exercisers the vigor increased and fatigue decreased after a workout session and there was no improvement in the vigor levels of non-exercisers.

The present research also revealed a significant difference in participants with different frequencies of exercise with respect to the dimension of Investment in Ideals, which means that size and muscle definition mattered more to regular exercisers and moderate exercisers when compared to non-exercisers. There is also a significant difference in participants with different frequencies of exercise with respect to the dimension of Attention to Grooming, which means that attention to appearance and dressing, was more in the moderate exerciser group when compared to the regular and non-exerciser group. This finding can be supported by a study conducted by Daniels and Niekerk (2011), which found that moderate exercise patterns had a significant effect on the attention to grooming dimension of body-self image, when compared to non-exercisers. The current study highlighted a significant difference in participants with different frequencies of exercise with respect to Dieting dimension. In other words regular and moderate exercisers engaged more in dieting behaviors and controlling body fat when compared to non-exercisers. The finding can be supported by the study conducted by Furnham andBoughton (1995), which reported dieting practices to be more predominant in regular exercisers.

The current research emphasizeda significant difference between men and women with respect to the dimension of social dependence, domain of Physical Health, Psychological Health and domain of Environment. Women scored higher than men with respect to the dimension of social dependence. Supporting these results, a study concluded women put greater importance to appearance and were more aware of their body in social situations (Davis \& Cowles, 1991).

The current study also highlighted a significant interaction effect between frequency of exercise and gender with respect to the dimension of Fatness Evaluation, consistent results were found by Robertson andVohora (2008),concluding women exercisers were more conscious of their body fat than men exercisers. The current study also found that there was a significant interaction effect between frequency of exercise and gender with respect to the dimension of Dieting, in line with this, a study found significant difference between men and women exercisers with respect to weight preoccupation, dieting and eating attitudes (Davis \& Fox, 1993). The current study found a significant interaction effect between frequency of exercise and gender with respect to the dimension of social relationships, environment and dimension of Health/Fitness Influence. A study conducted by Tiggemann and Williamson(2000), found that there was a significant difference between men and women exercisers with respect to fitness levels.

The present study revealed significant negative correlations between the dimension of Fatness evaluation and the dimensions of physical health, Psychological health and social relationships in regular exercisers. A study found, increased body fatness gave rise to mood disturbances, depression, disturbed 
interpersonal relationships and health related problems, hence if body fatness was controlled it would have a positive impact on physical and psychological health (Stewart \& Turner, 2003).

The current study also emphasized significant negative correlations between the dimension of Negative affect and the dimensions of physical health and Psychological health in regular exercisers. The study also revealed a significant negative correlation between the dimension of Social dependence and the dimension of Psychological health. A similar study found that when surrounded by people, the stress levels, insecurity levels increased for individuals (Wilkinson \& Marmot, 2003). The present study also shows a significant negative correlation between eating attitudes and Quality of life in regular exercisers. Similarly, French and Jeffery (1994), found that dieting had a negative impact on physical and psychological domains of quality of life. Hence the above study supports the finding as when the eating attitudes of an individual are healthier the negative effects on quality of life can be reduced.The current study also shows significant positive correlations between overall appearance evaluation dimension and physical health dimension in regular exercisers. Nicpon and Blanks (2005),established that women exercisers had a poorer body image and appearance evaluation as compared to men exercisers and both the groups engaged in regular physical exercise for physical health related reasons.

The current research also pointed significant positive correlations between Fatness evaluation dimension and dimensions of Dieting, Bulimia and Food Preoccupation and Oral control in regular exercisers. In a study conducted by Donaghue and Allen (2015), it was found that exercisers were motivated to lose weight and fat for social concerns and were motivated to engage in dieting practices. Hence the latter study supports the finding.

The present study also showed significant positive correlations between Health/Fitness evaluation dimension and dimensions of Psychological health and environment in regular exercisers, this finding can be supported by a study conducted by Hassmen (2000), which found that regular exercisers had a positive impact on controlling stress levels, mood disturbances. The study found that regular exercisers perceived their health to be better. The present study also shows significant positive correlations between Negative affect dimension and dimensions of Dieting and Bulimia and Food Preoccupation in regular exercisers.

The present study also revealed significant positive correlations between Health/Fitness influence and Social dependencedimension and dimensions of dieting, Bulimia and Food Preoccupation and Oral control in regular exercisers.A study conducted by Atalay and Gencoz (2008), supports this finding. In the latter study it was seen that socially conscious exercisers engaged in abnormal eating behaviors.

The present study also showed significant positive correlations between Dimension of Investment in ideals and dimensions of dieting, Attention to grooming dimension and Oral control in regular exercisers. Likewise, Grogan and Richards (2002), found that muscle definition was important to stay fit and toned in regular exercisers and that to achieve a good defined body, eating attitudes and behaviors would have to be healthy, this study supports the finding and shows a positive correlation between investment in ideals i.e. importance of muscle definition and engaging in healthy eating attitudes.

The present study revealed that there are significant negative correlations between the dimension of Bulimia and Food Preoccupation and dimensions of Overall appearance evaluation in moderate exercisers.The present study revealed significant negative correlations between Social relationships and Psychological health in moderate exercisers. A similar study by Taylor andSallis (1985), which found that moderate physical activity improved social skills and cognitive functions. The present study shows that there are significant negative correlations Fatness evaluation dimension and psychological health dimension in moderate exercisers. The study also pointed significant negative correlations between the Health/Fitness evaluation dimension and Bulimia and Food Preoccupation in moderate exercisers. There are significant negative correlations between Negative affect dimension and Psychological health dimension in moderate exercisers.

The present research showed significant positive correlations between Overall appearance evaluation dimension and dimensions of Psychological health and Environment in moderate exercisers. Consistent with the results, Fox (1999), found that moderate physical activity can improve self-perception and evaluation of one's self and can be instrumental in improving self-esteem and reducing anxiety.The current study revealed significant positive correlations between Fatness evaluation dimension and dimensions of Bulimia and Food Preoccupation and Dieting in moderate exercisers.The present study also showed significant positive correlations between Health/Fitness evaluation dimension and dimension of Psychological health in moderate exercisers. This finding can be supported by a study conducted by Plante and Rodin (1990), which found that moderate physical activity, and better psychological health can be positively linked. The present study also pointed significant positive correlations between Negative affect dimension and dimensions of dieting and Bulimia and Food Preoccupation in moderate exercisers. This finding can be supported by a study conducted by Lipsey and Barton (2006), which found that there was a positive correlation between exercise and eating disorders. The present study shows also shows significant positive correlations between Social dependence dimension and dimension of Bulimia and Food Preoccupation in moderate exercisers. 
The present study highlighted significant negative correlation between Height dissatisfaction dimension and dimension of physical health. In other words, more the dissatisfaction with height of the non- exercisers, the lesser was their ability to work and engage in daily life activities.

The current study emphasized significant positive correlation between Overall appearance evaluation dimension and physical health dimension in non- exercisers. The present pointed a significant positive correlation between Fatness evaluation dimension and dieting dimension in non- exercisers. The present study showed a significant positive correlation between Health/Fitness evaluation dimension and dimensions of physical health, Psychological health, environment and social relationships. This finding can be supported by a study conducted by Penedo andDahn (2005), which found that fitness could be positively correlated with better quality of life and well being. Hence if the non- exercisers engaged in physical activity their mental health would improve.The present study revealed a significant positive correlation between Negative affect dimension and oral control dimension of eating attitudes in non- exercisers. This finding can be supported by a study conducted byStice (1998), which found that bulimic symptoms were positively correlated with negative affect.

In conclusion, the study revealed significant differences in participants with different frequencies of exercise (viz., regular, moderate and non-exercise) with respect to the Heath/Fitness Evaluation, Heath/Fitness Influence, Investment in ideals, Attention to grooming, Dieting dimension of body self-image and eating attitudes respectively. Significant differences between men and women were observed with respect to the Social dependence dimension of body self-image and Physical Health, Psychological health and environment dimensions of Quality of life.Significant interaction effects between frequency of exercise (viz., regular, moderate and non- exerciser) and gender were observed with respect to Fatness evaluation, Negative affect and Health/Fitness Influence dimensions of body self-image, Dieting and Oral control dimensions of Eating attitudes and Social relationships and Environment dimensions of Quality of life. Also significant negative and positive correlations between the dimensions of Body Self Image, Eating Attitudes and Quality of Life were observed in the three frequency of exercise groups.

The current study revealed that even moderate exercisers have a better quality of life and positive selfperception when compared to regular exercisers, hence working out at least three times a week is advised to those individuals who do not engage in exercise at all. The study highlights the need to bring about awareness in schools, colleges and work places about the importance of physical exercise and its effect on building positive self-perception and self-esteem and thereby improve the quality of life and levels of happiness in individuals.

\section{REFERENCES}

[1] Abrams, K. K., Allen, L. R., \& Gray, J. J. (1993). Disordered eating attitudes and behaviors, psychological adjustment, and ethnic identity: A comparison of Black and White female college students.International Journal of Eating Disorders, 14(1), 49-57.

[2] Alexander, K., \&Hausenblas, M. (2009). Describing linked datasets-on the design and usage of void, the'vocabulary of interlinked datasets. In In Linked Data on the Web Workshop (LDOW 09), in conjunction with 18th International World Wide Web Conference (WWW 09)

[3] Alvarenga Dos Santos, M., Scagliusi, F. B., \& Philippi, S. T. (2010). Eating attitudes of female Brazilian university students with eating disorder risk behavior. Journal of Behavior, Health \& Social Issues, 2(1), 47-54.

[4] Atalay, A. A., \&Gençöz, T. (2008). Critical factors of social physique anxiety: Exercising and body image satisfaction. Behaviour Change, 25(03), 178-188.

[5] Bridges, B. (1993). Occupational therapy evaluation for patients with eating disorders. Occupational therapy in mental health, 12(2), 79-89.

[6] Bordo, S. (1993).Feminism, Foucault and the politics of the body1. Up against Foucault: Explorations of some tensions between Foucault and feminism, 179.

[7] Campbell, A., \&Hausenblas, H. A. (2009). Effects of Exercise Interventions on Body Image A Metaanalysis. Journal of health psychology, 14(6), 780-793.

[8] Casazza, K., Fontaine, K. R., Astrup, A., Birch, L. L., Brown, A. W., Bohan Brown, M. M., ... \& McIver, K. (2013). Myths, presumptions, and facts about obesity. New England Journal of Medicine, 368(5), 446454.

[9] Cash, T. F. (2004). Body image: Past, present, and future. Body image, 1(1), 1-5.

[10] Cash, T. F., \&Pruzinsky, T. E. (1990). Body images: Development, deviance, and change. Guilford Press.

[11] Caspersen, C. J., Powell, K. E., \& Christenson, G. M. (1985). Physical activity, exercise, and physical fitness: definitions and distinctions for health-related research. Public health reports, 100(2), 126.

[12] Collett, M. J., \& Gardiner, C. W. (1984). Squeezing of intracavity and traveling-wave light fields produced in parametric amplification. Physical Review A, 30(3), 1386.

[13] Cororve, M. B., \&Gleaves, D. H. (2001). Body dysmorphic disorder: a review of conceptualizations, assessment, and treatment strategies. Clinical Psychology Review, 21(6), 949-970. 
[14] Daniels, A. K., \& Van Niekerk, R. L. (2011).The influence of a moderate aerobics programme on the body self-image of women in middle adulthood.South African Journal of Sports Medicine, 23(4).

[15] Davis, C. (1992). Body image, dieting behaviours, and personality factors: A study of high-performance female athletes. International Journal of Sport Psychology.

[16] Davis, C., Fox, J., Cowles, M., Hastings, P., \&Schwass, K. (1990). The functional role of exercise in the development of weight and diet concerns in women. Journal of Psychosomatic Research, 34(5), 563-574.

[17] Davis, C., \& Cowles, M. (1991). Body image and exercise: A study of relationships and comparisons between physically active men and women. Sex Roles, 25(1-2), 33-44.

[18] Davis, C., \& Fox, J. (1993).Excessive exercise and weight preoccupation in women. Addictive Behaviors, 18(2), 201-211

[19] Donaghue, N., \& Allen, M. (2015). "People don't care as much about their health as they do about their looks": Personal trainers as intermediaries between aesthetic and health-based discourses of exercise participation and weight management. International Journal of Sport and Exercise Psychology, 1-15.

[20] Folkins, C. H., \& Sime, W. E. (1981).Physical fitness training and mental health. American Psychologist, 36(4), 373.

[21] Fox, K. R. (1999). The influence of physical activity on mental well-being.Public health nutrition, 2(3a), 411-418.

[22] Franklin, B. A., \& Garber, C. E. (1998).American College of Sports Medicine Position Stand.The recommended quantity and quality of exercise for developing and maintaining cardiorespiratory and muscular fitness, and flexibility in healthy adults. Med Sci Sports Exerc, 30(6), 975-91.

[23] Fredrickson, B. L., Roberts, T. A., Noll, S. M., Quinn, D. M., \&Twenge, J. M. (1998). That swimsuit becomes you: sex differences in self-objectification, restrained eating, and math performance. Journal of personality and social psychology, 75(1), 269.

[24] French, S. A., \& Jeffery, R. W. (1994). Consequences of dieting to lose weight: effects on physical and mental health. Health Psychology, 13(3), 195.

[25] Furnham, A., \&Boughton, J. (1995).Eating behaviour and body dissatisfaction among dieters, aerobic exercisers and a control group.European Eating Disorders Review, 3(1), 35-45.

[26] Garner, D. M., \&Garfinkel, P. E. (1985). Handbook of psychotherapy for anorexia nervosa and bulimia.Guilford Press.

[27] Garner, D. M., Olmsted, M. P., Bohr, Y., \&Garfinkel, P. E. (1982). The eating attitudes test: psychometric features and clinical correlates. Psychological medicine, 12(04), 871-878.

[28] Grilo, C. M., Wilfley, D. E., Brownell, K. D., \& Rodin, J. (1994).Teasing, body image and self-esteem in a clinical sample of obese women. Addictive Behaviors, 19(4), 443-450.

[29] Grogan, S., \& Richards, H. (2002).Body image focus groups with boys and men. Men and masculinities, 4(3), 219-232.

[30] Grant, C. L., \& Fodor, I. G. (1986).Adolescent attitudes toward body image and anorexic behavior. Adolescence, 21(82), 269.

[31] Hales, R. E., \& Travis, T. W. (1987). Exercise as a treatment option for anxiety and depressive disorders. Military medicine.

[32] Hansen, C. J., Stevens, L. C., \& Coast, J. R. (2001). Exercise duration and mood state: How much is enough to feel better? Health Psychology, 20(4), 267

[33] Hassmen, P., Koivula, N., \&Uutela, A. (2000). Physical exercise and psychological well-being: a population study in Finland. Preventive medicine, 30(1), 17-25.

[34] Harrison, K., \& Cantor, J. (1997).The relationship between media consumption and eating disorders. Journal of Communication, 47(1), 40-67.

[35] Hausenblas, H. A., \& Fallon, E. A. (2006). Exercise and body image: A meta-analysis. Psychology and Health, 21(1), 33-47.

[36] Hoffman, M. D., \& Hoffman, D. R. (2008). Exercisers achieve greater acute exercise-induced mood enhancement than nonexercisers. Archives of physical medicine and rehabilitation, 89(2), 358-363.

[37] Hrabosky, J. I., Cash, T. F., Veale, D., Neziroglu, F., Soll, E. A., Garner, D. M., ...\& Phillips, K. A. (2009). Multidimensional body image comparisons among patients with eating disorders, body dysmorphic disorder, and clinical controls: A multisite study. Body image, 6(3), 155-163.

[38] Hurd, L. C. (2000). Older women's body image and embodied experience: An exploration. Journal of Women \& Aging, 12(3-4), 77-97.

[39] Krane, V., Waldron, J., Stiles-Shipley, J. A., \&Michalenok, J. (2001).Relationships among body satisfaction, social physique anxiety, and eating behaviors in female athletes and exercisers. Journal of Sport Behavior,24(3), 247. 
[40] Lipsey, Z., Barton, S. B., Hulley, A., \& Hill, A. J. (2006). “After a workout...” Beliefs about exercise, eating and appearance in female exercisers with and without eating disorder features. Psychology of Sport and Exercise, 7(5), 425-436.

[41] Lowery, S. E., Nicpon, M. F., Blanks, E. H., Befort, C., Kurpius, S. E. R., Sollenberger, S., \&Huser, L. (2005).Body image, self-esteem, and health-related behaviors among male and female first year college students. Journal of College Student Development, 46(6), 612-623.

[42] Maloney, M. J., McGuire, J., Daniels, S. R., \&Specker, B. (1989). Dieting behavior and eating attitudes in children. Pediatrics, 84(3), 482-489.

[43] McCarthy, M. (1990).The thin ideal, depression and eating disorders in women. Behavior research and therapy, 28(3), 205-214

[44] McTiernan, A., Sorensen, B., Irwin, M. L., Morgan, A., Yasui, Y., Rudolph, R. E., \& Potter, J. D. (2007). Exercise effect on weight and body fat in men and women. Obesity, 15(6), 1496-1512.

[45] Mond, J. M., Hay, P. J., Rodgers, B., Owen, C., \&Beumont, P. J. (2004).Validity of the Eating Disorder Examination Questionnaire (EDE-Q) in screening for eating disorders in community samples. Behavior research and therapy, 42(5), 551-567.

[46] Morry, M. M., \&Staska, S. L. (2001). Magazine exposure: Internalization, self-objectification, eating attitudes, and body satisfaction in male and female university students. Canadian Journal of Behavioural Science/Revue canadienne des sciences du comportement, 33(4), 269.

[47] Myers, P. N., \&Biocca, F. A. (1992). The elastic body image: The effect of television advertising and programming on body image distortions in young women. Journal of communication, 42(3), 108-133.

[48] Paluska, S. A., \&Schwenk, T. L. (2000).Physical activity and mental health.Sports medicine, 29(3), 167180.

[49] Penedo, F. J., \&Dahn, J. R. (2005). Exercise and well-being: a review of mental and physical health benefits associated with physical activity. Current opinion in psychiatry, 18(2), 189-193.

[50] Piqueras, J. A., Kuhne, W., Vera-Villarroel, P., van Straten, A., \&Cuijpers, P. (2011). Happiness and health behaviours in Chilean college students: a cross-sectional survey. BMC Public Health, 11(1), 1.

[51] Plante, T. G., \& Rodin, J. (1990).Physical fitness and enhanced psychological health. Current psychology, 9(1), 3-24.

[52] Pollock, M. L., Gaesser, G. A., Butcher, J. D., Després, J. P., Dishman, R. K., Franklin, B. A., \& Garber, C. E. (1998). ACSM position stand: the recommended quantity and quality of exercise for developing and maintaining cardiorespiratory and muscular fitness, and flexibility in healthy adults. Med Sci Sports Exerc, 30(6), 975-991.

[53] Polivy, J., \& Herman, C. P. (1985). Dieting and binging: A causal analysis.American Psychologist, 40(2), 193.

[54] Prichard, I., \&Tiggemann, M. (2008). Relations among exercise type, self-objectification, and body image in the fitness centre environment: The role of reasons for exercise. Psychology of sport and exercise, 9(6), 855-866.

[55] Roberts, A., Cash, T. F., Feingold, A., \& Johnson, B. T. (2006). Are black-white differences in females' body dissatisfaction decreasing? A meta-analytic review. Journal of consulting and clinical psychology, 74(6), 1121.

[56] Roberts, K., \& Marvin, K. (2011). Knowledge and attitudes towards healthy eating and physical activity: what the data tell us. National Obesity Observatory, Oxford.

[57] Rodin, J., Silberstein, L., \&Striegel-Moore, R. (1984). Women and weight: a normative discontent. In Nebraska symposium on motivation.University of Nebraska Press.

[58] Robertson, N., \&Vohora, R. (2008). Fitness vs. fatness: Implicit bias towards obesity among fitness professionals and regular exercisers. Psychology of Sport and Exercise, 9(4), 547-557.

[59] Rowe, D. A., Benson, J., \& Baumgartner, T. A. (1999). Development of the body self-image questionnaire. Measurement in Physical Education and Exercise Science, 3(4), 223-247.

[60] Sallis, J. F., \& Patrick, K. (1994). Physical activity guidelines for adolescents: consensus statement. Pediatric exercise science, 6, 302-302.

[61] Sharps, M. J., Price-Sharps, J. L., \& Hanson, J. (2001). Body image preference in the United States and rural Thailand: An exploratory study. The Journal of psychology, 135(5), 518-526.

[62] Siever, M. D. (1994). Sexual orientation and gender as factors in socioculturally acquired vulnerability to body dissatisfaction and eating disorders. Journal of consulting and clinical psychology, 62(2), 252.

[63] Stice, E. (1998). Relations of restraint and negative affect to bulimic pathology: A longitudinal test of three competing models. International Journal of Eating Disorders, 23(3), 243-260.

[64] Stewart, K. J., Turner, K. L., Bacher, A. C., DeRegis, J. R., Sung, J., Tayback, M., \& Ouyang, P. (2003). Are fitness, activity, and fatness associated with health-related quality of life and mood in older persons?.Journal of Cardiopulmonary Rehabilitation and Prevention, 23(2), 115-121. 
[65] Stunkard, A., \& Mendelson, M. (1967). Obesity and the body image: I. Characteristics of disturbances in the body image of some obese persons.American Journal of Psychiatry, 123(10), 1296-1300.

[66] Stubbe, J. H., De Moor, M. H. M., Boomsma, D. I., \& De Geus, E. J. C. (2007). The association between exercise participation and well-being: a co-twin study. Preventive medicine, 44(2), 148-152.

[67] Taylor, C. B., Sallis, J. F., \& Needle, R. (1985).The relation of physical activity and exercise to mental health. Public health reports, 100(2), 195.

[68] Touyz, S. W., Beumont, P. J., Collins, J. K., \& Cowie, I. (1985).Body shape perception in bulimia and anorexia nervosa. International Journal of Eating Disorders, 4(3), 259-265.

[69] Tiggemann, M., \& Williamson, S. (2000). The effect of exercise on body satisfaction and self-esteem as a function of gender and age. Sex roles,43(1), 119-127.

[70] WHOQOL group. (1995). The World Health Organization quality of life assessment (WHOQOL): position paper from the World Health Organization. Social science \& medicine, 41(10), 1403-1409.

[71] Wilkinson, R. G., \& Marmot, M. G. (2003). Social determinants of health: the solid facts. World Health Organization.

[72] Yee, H. C. (1987). Construction of explicit and implicit symmetric TVD schemes and their applications. Journal of Computational Physics, 68(1), 151-179.

[73] Zhao, Y., Christensen, S. K., Fankhauser, C., Cashman, J. R., Cohen, J. D., Weigel, D., \&Chory, J. (2001). A role for flavin monooxygenase-like enzymes in auxin biosynthesis. Science, 291(5502), 306309. 